\title{
WP 0307
}

ELENA KETTENI

University of Cyprus

THEOFANIS MAMUNEAS

University of Cyprus

THANASIS STENGOS

University of Guelph

and

Rimini Centre for Economic Analysis

\section{"THE EFFECT OF INFORMATION TECHNOLOGY AND \\ Human Capital on ECONOMIC GROWTH"}

Copyright belongs to the author. Small sections of the text, not exceeding three paragraphs, can be used provided proper acknowledgement is given.

The Rimini Centre for Economic Analysis (RCEA) was established in March 2007. RCEA is a private, non-profit organization dedicated to independent research in Applied and Theoretical Economics and related fields. RCEA organizes seminars and workshops, sponsors a general interest journal The Review of Economic Analysis, and organizes a biennial conference: Small Open Economies in the Globalized World (SOEGW). Scientific work contributed by the RCEA Scholars is published in the RCEA Working Papers series.

The views expressed in this paper are those of the authors. No responsibility for them should be attributed to the Rimini Centre for Economic Analysis. 


\title{
The Effect of Information Technology and Human Capital on Economic Growth
}

\author{
Ketteni Elena Mamuneas Theofanis Stengos Thanasis
}

August 7, 2006

\begin{abstract}
In this paper we compare the impact of hardware, software and communication equipments, widely referred to as information and communication technologies (ICT) on economic growth among the advanced industrialized countries. We use nonparametric techniques that allow us to directly estimate the elasticity of ICT and human capital for each country and time period. We also examine whether the nonlinear relationship between human capital and growth, found in the literature, still persists in the presence of ICT effects. The data covers the period from 1980-2004, for a range of OECD countries and the results indicate that there exist a nonlinear relationship between ICT and productivity along with a nonlinear relationship between human capital and productivity. Additionally, we observe that in high levels of ICT capital the output elasticities of human capital are larger and the more educated workers in a country the higher are the output elasticities of ICT.
\end{abstract}




\section{Introduction}

In recent years, economists have observed a rapid diffusion of information technology (IT) or generally referred to as information and communication technology (ICT) software and hardware throughout the world. At the same time the US economy and the economies of other industrialized countries have experienced a protracted period of high growth and low inflation, something that is generally attributed to the development and application of information technologies. Some economists suggest that this fact is a direct consequence of the dramatic decline in the price of computers, which has led to a substitution of ICT equipment for other forms of capital and labor. It has been suggested, that this substitution generates substantial returns for agents who undertake ICT investment and also has had a very significant impact on economic growth. This view has given rise to a vigorous debate among economists. On the one hand, it is argued that the development of ICT is one of a series of positive temporary shocks and it has no effect on productivity and growth. On the other hand, there is the claim that ICT has produced a fundamental change in the economy leading to a permanent improvement in growth prospects. This debate can furthermore be better understood as a result of Solow's "Computer Productivity Paradox", coined by Solow (1957) who suggested that "You can see the computer age everywhere but in the productivity statistics". The bulk of this research has examined the relationship between ICT and productivity for the US economy and to a lesser extent for some individual countries such as Germany, France and Japan.

The contribution of our study is that we go beyond what has been done so far in the literature in terms of a few individual countries and compare the productivity performance and the impact of hardware, software and communication 
equipment on economic growth for the group of the advanced industrialized countries (OECD) as a whole. As far we know there is no clear cut evidence of the impact of ICT on the productivity in these countries. Furthermore, we study the interaction and influence of ICT on the return of human capital and growth. There is some limited evidence from the US as mentioned above that the wage differentials observed between high-skilled and low-skilled labor are due to the higher educational attainments of skilled labor. One of our main objectives is to establish the presence of possible interactions between ICT and human capital. We use nonparametric techniques to examine the impact of ICT capital to the process of productivity growth by allowing the contribution of various inputs (including human capital) as well as that of ICT capital to vary across countries and time. This is accomplished firstly, by constructing an index of Total Factor Productivity (TFP) based on only non-human capital labor and non-ICT capital inputs and secondly, by using this index to evaluate the impact of ICT and human capital on TFP growth via semiparametric methods. The smooth coefficient semiparametric model that we use, allows us to directly estimate the elasticity of ICT and human capital for each country and each time period. In addition we are able to estimate the interaction between the human capital and ICT in order to find the interrelationship between human capital and information technology. The recent literature examining the effect of human capital on economic growth suggests that there exists a nonlinear relationship between human capital and economic growth, see Kalaitzidakis et al (2001) and Mamuneas, Savvides and Stengos (2006). In light of the limited country specific evidence regarding the interactions between different types of labor and ICT presented above, we would like to see whether this nonlinear relationship between human capital and growth still persists in the presence of ICT effects. To put it differently, we would like to see whether this nonlinearity was the result 
of an omitted ICT effect. This is the first study as far as we know that attempts to do that in the empirical growth literature. OECD provides a wide range of country members' data for the period 1980 to 2004. The countries used in this analysis are: Austria, Belgium, Denmark, Finland, France, Germany, Greece, Ireland, Italy, Netherlands, Portugal, Spain, Sweden, UK and USA. OECD provides data on investment of IT equipment, communication equipment, Software, Non-ICT equipment, Transportation equipment, and non Residential Structures for each country along with employment and GDP data. The human capital stock data are obtained from Vikram and Dhareshwar (1993). These data covers the period 1950 to 1990 and the human capital stock is defined as total mean year's education. With the use of the Barro and Lee (2001) data base, applying extrapolation techniques we are able to expand the human capital stock up to 2004. The results indicate that there exists a nonlinear relationship between ICT and productivity along with a nonlinear relationship between human capital and productivity. The nonlinear relationship between human capital and productivity found previously in the literature still holds in the presence of ICT effects. Additionally the smooth coefficient semiparametric model indicates that in high level of ICT capital the output elasticities of human capital are larger and in high levels of human capital, measured by mean years of schooling, we obtain higher output elasticities of ICT capital. The rest of the paper is organized as follows. Section 2 presents the literature review, section 3 discusses the methodology and the data sources, section 4 presents the estimation results and section 5 concludes. 


\section{Literature Review}

As mentioned above, the bulk of the literature has examined the relationship between ICT and productivity for the US economy and to a lesser extent for some individual countries such as Germany, France and Japan. Most of the early evidence based on aggregate US data, suggests that ICT and especially computers have had no effect on either productivity or growth. These studies were based on an aggregate production function assume constant returns to scale and competitive markets, while factor shares are often used as a proxy for output elasticities. Clearly, under the above assumptions, these models will have likely missed important variation in the data among different industries. In that line of research Berndt and Morrison (1995), and Morrison (1997) examine the extent to which investment in high - tech office and ICT capital has reduced costs and has facilitated productivity growth using aggregate manufacturing data for the periods 1968 to 1986 and 1952 to 1986 respectively and they find little evidence that this is the case. Jorgenson and Stiroh (1999) employing aggregate US data from 1990 to 1996 also find similar results, whereas Jorgenson (2001) indicates that the contribution of IT increased, but more than 70 percent of the increased output can be attributed to non - ICT products. Similarly, Gordon (2000) explores some of the intrinsic limitations of computers in general and the internet in particular for affecting productivity and quality of life when evaluated in comparison to the great inventions of the past and he concludes that computer investment has had a near zero rate of return outside of durable manufacturing and seventy five percent of all computer investment has been in industries with no trend increase in productivity. On the whole, aggregate studies indicate no significant relationship between productivity growth and high-tech capital.

However, more recent studies relying primarily on the use of industry or sec- 
toral data indicate that ICT is indeed playing a major role in the productivity of an economy. They claim that firms and industries that produce ICT assets have experienced considerable growth and benefited from the extraordinary technological progress. This in turn has enabled them to improve the performance of ICT goods, measured as total factor productivity (TFP) growth in the ICT - producing industries. Siegel (1997), using detailed industry data estimates a multiple - indicators, multiple causes model that allows for the estimation of the relationship between computer usage and product (or labor) quality, while controlling for measurement errors and finds a positive and statistically significant relationship between productivity growth and investment in computers. In that context, the productivity paradox, or the absence of a positive correlation between computers and productivity growth at least in the manufacturing sector, could be a statistical illusion that can be attributed to measurement error. Barua and Lee (1997), and Stiroh $(1998,2002)$ find that the impact of ICT related industries on aggregate U.S. productivity growth is quantitatively large and economically important. Feldstein (2003), also finds that productivity in the US has been growing faster in the past seven years than it did in the previous quarter century, while Jorgenson, Stiroh and Ho (2002), estimate the economy wide sources of growth for the period 1958 to 1999 and various subperiods using industry level data through a production possibility frontier approach for ICT - producing and non -IT producing industries. Their results indicate a rising contribution of ICT - producing industries to U.S. economic growth.

With regard to non US studies, Biscourp et. al. (2002), using a panel of 5000 French firms between 1994 and 1997 estimate a translog production function, to investigate how the decrease in the cost of computers has affected the marginal cost of firms, their aggregate labor demand and their skill structure and they find a strong but heterogeneous effect across firms. Also Matteucci 
et al (2005), in their paper consider the contribution of ICT to international productivity performance. They use an international industry data set within a growth accounting framework to show that ICT has typically had a lower impact on productivity in Europe than in the US, although there is a considerable variation within Europe. The paper also analyses the European situation in greater depth by examining micro-economic data from Germany, Italy and the UK. The results suggest that the UK experience with ICT has been closer to the US than other European countries. In another paper Basu et al (2003), find in both US and UK a strong correlation between ICT use and industry TFP growth. The US results indicate that the TFP acceleration was located primarily in ICT-using industries and is positively correlated with industry ICT capital growth from the 1980s and early 1990s. A somewhat different picture emerges for the UK. TFP growth does not appear correlated with lagged ICT capital growth. But TFP in the late 1990s is strongly and positively associated with the growth of ICT capital services while being strongly and positively associated with the growth of ICT investment. Jorgensosn and Motohashi (2005), compare sources of economic growth in Japan and the United States from 1975 through 2003, focusing on the role of ICT. The authors have adjusted Japanese data to conform to US definitions. The adjusted data show that the share of Japanese gross domestic product devoted to investment in computers, telecommunication equipment, and software rose sharply after 1995. The contribution of total factor productivity from the IT sector in Japan also increased, while the contributions of labor input and productivity growth from the non-IT sector lagged behind the US. Hoon (2003), in his paper explores the impact of ICT investment on economic growth using a cross-country analysis based on data from 56 developing countries for the years 1970-1998. He considers an augmented neoclassical model based on Mankiw et al (1992), assuming a Cobb- Douglas 
production function and he finds using standard linear econometric methods that ICT significantly contributes to economic growth in the developing world.

Another issue arising in the ICT literature, has been the substitution of information technology equipment for other forms of capital and labor inputs. A number of papers in the literature have investigated the relationship between ICT and labor demand. They indicate that ICT causes the relative demand for more highly educated and experienced workers, as well as the relative demand for highly skilled workers to rise. ICT - based production processes also causes substitution for low skill human work. This is referred in the literature as skill - biased technical change (SBTC). Some economists argue that this SBTC has caused the wage inequality that has appeared in the U.S. economy. One line of research in this area has been concerned with the effect of information technology on the relative demand for workers with different education and skill levels. Chun (2003), examines both the use and adoption effects of ICT on the relative demand for educated workers, using data from 56 US industries for the period 1960-1996. His findings suggest that educated workers have a comparative advantage in the adoption of ICT and that the total ICT effect accounts for almost 40 percent of the acceleration in the rate of relative demand growth for educated workers since 1970. Bermand, Bound and Grilliches (1994), have investigated shifts in the demand away from unskilled and towards skilled labor in the US manufacturing over the 1980s. Their results suggest that this shift is due mostly to increased use of skilled workers within the industries rather than to a reallocation of employment between industries. Additionally, they indicate that increased use of non-production workers is strongly correlated with investment in computers and research and development (R\&D). Autor, Katz and Krueger (1997) examine the effects of technological change and other factors on the relative demand for workers with different education levels and on 
the recent growth of US educational differentials. Their results indicate that the relative demand for college graduates grew more rapidly on average during 1970 to 1995 than during 1940 to 1995 . The acceleration in demand for more skilled workers is entirely accounted for by an increase in within-industry changes in skill utilization rather than between industry employment shifts. They also suggest that the spread of computer technology may "explain" as much as 30 to 50 percent of the increase in the rate of growth of the relative demand for more skilled workers since 1970. Bermand et al (1998), find strong evidence for pervasive SBTC in developing countries. They conclude that SBTC was not only the major cause of decreased demand for less-skilled workers in the US, but also shifted demand from less-skilled to skilled workers throughout the developed world. Falk and Stein (2001), use data for 1000 West German firms located in the service sector and they find a significant relationship between firms skill structure and their ICT investment output ratios. They suggest that ICT serves as a substitute to unskilled labor and complement to both medium and high skills labor especially those who can efficiently use newly introduced ICT structures. They indicate that the fall in demand for low skilled labor results from the systematic substitution of computers for human decision making. Bresnahan, Brynjolfsson and Hitt (2002) examine how information technology could cause skill-biased technical change. They use for their estimation a panel data set of 400 U.S. firms which covers the period between 1987 and 1994. They find that intensive use of ICT, higher service level for customers and organizational change all go together, and together call for higher skilled labor. The above evidence suggests that ICT causes the relative demand for more highly educated and experienced (skilled) workers to rise, while it causes the relative demand for low-skilled workers to decrease. 


\section{Methodology and Data Sources}

\subsection{Specification}

To examine our primary goal, based on the data available we will assume a general production function written as follows:

$$
Y=F(P, E, t)
$$

where $Y$ is the total output, $P$ is the total physical capital (including ICT capital), $E$ is effective or human-capital augmented labor and $t$ is a technology index measured by time trend. Total differentiation of (1) with respect to time and division by $Y$ yields:

$$
\hat{Y}=\hat{A}+\varepsilon_{P} \hat{P}+\varepsilon_{E} \hat{E}
$$

where $\left({ }^{\wedge}\right)$ denotes a growth rate, $\hat{A}=\frac{(\partial F / \partial t)}{Y}$ is the exogenous rate of technological change and $\varepsilon_{i}=\frac{\partial \ln Y}{\partial \ln Q},(i=P, E)$ denotes output elasticity. Equation (2) however, is not useful for empirical purposes because the growth rate of effective labor $\hat{E}$ is not observable and because we also want to estimate the effect of ICT capital. Assuming that the effective labor input is a function of the labor force, $L$, and average human capital, $H$, we have $E=\Phi(L, H)$. Similarly the total physical capital is assumed to be a function of physical capital (excluding ICT capital), $K$, and ICT capital, $I$,. i.e., $P=\Psi(K, I)$. Then we can decompose $\hat{E}$ and $\hat{P}$ as:

$$
\begin{gathered}
\hat{E}=\eta_{L} \hat{L}+\eta_{H} \hat{H} \\
\hat{P}=\eta_{K} \hat{K}+\eta_{I} \hat{I}
\end{gathered}
$$

where $\eta_{L}$ and $\eta_{H}$ are effective labor elasticities with respect to labor and average human capital, and $\eta_{K}$ and $\eta_{I}$ are total physical capital elasticities with respect to non-ICT capital and ICT capital respectively. Substituting (3) in (2) we 
have:

$$
\hat{Y}=\hat{A}+\varepsilon_{P}\left(\eta_{K} \hat{K}+\eta_{I} \hat{I}\right)+\varepsilon_{E}\left(\eta_{L} \hat{L}+\eta_{H} \hat{H}\right)
$$

Assuming a perfectly competitive environment, the output elasticities of labor and physical capital should be equal to the observed income shares of labor, $s_{Y L}$, and non-ICT capital, $s_{Y K}$. With data available for the above variables we can directly estimate the elasticities using panel or cross-sectional data methods. However, this is not the case for the output elasticity with respect to ICT capital or human capital since we want to examine simultaneously the relationship between ICT capital and productivity and human capital and productivity we follow an alternative specification. The approach that we follow here is an extension of Mamuneas, Savvides and Stengos (2005), who only considered the relationship between human capital and productivity. Firstly, we construct the TFP index (biased TFP index) based only on the labor and non-ICT capital. This index allows the contribution of each input to differ and to be dictated by the data. We define the Tornqvist index of TFP growth for country $i$ in year $t$ as follows:

$$
T \hat{F} P_{i t}=\hat{Y}_{i t}-w_{L i t} \hat{L}_{i t}-w_{K i t} \hat{K}_{i t}
$$

where $w_{Q i t}=0.5\left(s_{Q i t}+s_{Q i t-1}\right),(Q=L, K)$ are the weighted average cost shares of labor and non-ICT capital and $\hat{Q}_{i t}=\ln Q_{i t}-\ln Q_{i t-1},(Q=Y, L, K)$. This measure of TFP contains the components of output growth that can not be explained by the growth of the inputs $(K, L)$ in equation (4). Diewert (1976), suggested that this index is an exact index of technological change for a general translog production function, under certain conditions. In the second step we will use a nonparametric methodology to estimate the effect of ICT-capital and that of human capital on TFP growth. That is, we will model the contribution of ICT capital to aggregate production as a general unknown function $\theta_{1}(.) \hat{I}_{i t}$. Similarly, since we want to study the interaction and influence of ICT on the 
returns of human capital and growth, following results from the recent empirical growth literature of the effect of human capital on economic growth, see Kalaitzidakis et al (2001), who have shown the this effect is nonlinear, we also allow for the contribution of human capital to be $\theta_{2}(.) \hat{H}_{i t}$. Hence we have:

$$
T \hat{F} P_{i t}=\hat{A}_{i t}+\alpha \hat{Q}_{i t}+\theta_{1}(.) \hat{I}_{i t}+\theta_{2}(.) \hat{H}_{i t}
$$

where $\hat{Q}_{i t}=w_{K i t} \hat{K}_{i t}+w_{L i t} \hat{L}_{i t}$, and $a=(\rho-1)$ where $\rho=\varepsilon_{C Y}^{-1}$ is the elasticity of returns to scale of non-ICT capital and labor and $\varepsilon_{C Y}=\frac{\partial C / \partial Y}{Y / C}$ (cost flexibility). Semiparametric estimation of the above equation allows for testing the hypothesis of non-constant returns to scale in non-ICT capital and labor $(\alpha \neq 0)$. Also it allows ICT-capital accumulation, and human capital also, to influence TFP growth in a nonlinear fashion. In equation above, $\hat{A}_{i t}$ can be considered as a function of industry and year specific dummy variables. Country specific dummies, $D_{i}$, capture idiosyncratic exogenous technological change and time specific dummies, $D_{t}$, capture procyclical behavior of TFP growth. With regard to the unknown functions $\theta_{1}($.$) and \theta_{2}($.$) we assume that they depend$ on the level of ICT capital along with the human capital stock. The equation of interest now becomes:

$$
T \hat{F} P_{i t}=\alpha_{0}+\sum_{i=1}^{N-1} \alpha_{i} D_{i}+\sum_{t=1}^{T-1} \alpha_{t} D_{t}+\alpha \hat{Q}_{i t}+\theta_{1}(.) \hat{I}_{i t}+\theta_{2}(.) \hat{H}_{i t}+u_{i t}
$$

If we let $W_{i t}^{T}=\left(D_{i}, D_{t}, \hat{Q}_{i t}\right)$ and $V_{i t}=\left\{I_{i t}, H_{i t}, \Omega_{i t}\right\}$ where $\Omega_{i t}$ can be any other variable included in the smooth coefficient function, the model can be written more compactly as:

$$
T \hat{F} P_{i t}=W_{i t}^{T} \beta+\theta_{1}\left(V_{i t}\right) \hat{I}_{i t}+\theta_{2}\left(V_{i t}\right) \hat{H}_{i t}+u_{i t}
$$

For proper estimation we assume that $E\left(u_{i t} \mid W_{i t}, V_{i t}, \hat{I}_{i t}, \hat{H}_{i t}\right)=0$. Below we describe the estimation method that we will apply. 


\subsection{Econometric Estimation: A Smooth Coefficient Semi- parametric Approach}

A smooth coefficient semiparametric model is considered to be a useful and flexible specification for studying a general regression relationship with varying coefficients. It is a generalization of varying coefficient models and it is based on polynomial regression, see Fan (1992), Fan and Zhang (1999), Li et al (2002), Kourtellos (2003) and Mamuneas, Savvides and Stengos (2005) among others. A semiparametric varying coefficient model imposes no assumption on the functional form of the coefficients, and the coefficients are allowed to vary as smooth functions of other variables. Specifically, varying coefficient models are linear in the regressors but their coefficients are allowed to change smoothly with the value of other variables. One way of estimating the coefficient functions is by using a local least squares method with a kernel weight function. A semiparametric smooth coefficient model is given by:

$$
y_{i}=\alpha\left(z_{i}\right)+x_{i}^{\prime} \beta\left(z_{i}\right)+u_{i}
$$

where $y_{i}$ denotes the dependent variable (the TFP index as discussed earlier), $x_{i}$ denotes a $p \times 1$ vector of variables of interest (in the case of equation (5), $I \hat{T}_{i t}$ and $\left.\hat{H}_{i t}\right), z_{i}$ denotes a $q \times 1$ vector of other exogenous variables (the $V_{i t}=\left\{I T_{i t}, H_{i t}, \Omega_{i t}\right\}$ from equation (5) above) and $\beta\left(z_{i}\right)$ is a vector of unspecified smooth functions of $z_{i}\left(\theta_{1}(\right.$.$) and \theta_{2}($.$) in equation (5). To simplify the$

exposition, we ignore the partially linear nature of equation (5), by suppressing for now the vector of the $w / s$. Based on Li et. al. (2002), the above semiparametric model has the advantage that it allows more flexibility in functional form than a parametric linear model or a semiparametric partially linear specification. Furthermore, the sample size required to obtain a reliable semiparametric estimation is not as large as that required for estimating a fully nonparametric 
model. It should be noted that when the dimension of $z_{i}$ is greater than one, this model also suffers from the "curse of dimensionality", although to a lesser extent than a purely nonparametric model where both $z_{i}$ and $x_{i}$ enter nonparametrically. Fan and Zhang (1999), suggest that the appeal of the varying coefficient model is that by allowing coefficients to depend on other variables, the modelling bias can significantly be reduced and the curse of dimensionality can be avoided. Equation (6) above can be rewritten as

$$
\begin{gathered}
y_{i}=\alpha\left(z_{i}\right)+x_{i}^{T} \beta\left(z_{i}\right)+\varepsilon_{i}=\left(1, x_{i}^{T}\right)\left(\begin{array}{c}
\alpha\left(z_{i}\right) \\
\beta\left(z_{i}\right)
\end{array}\right)+\varepsilon_{i} \\
y_{i}=X_{i}^{T} \delta\left(z_{i}\right)+\varepsilon_{i}
\end{gathered}
$$

where $\delta\left(z_{i}\right)=\left(\alpha\left(z_{i}\right), \beta\left(z_{i}\right)^{T}\right)^{T}$ is a smooth but unknown function of $z$. One can estimate $\delta(z)$ using a local least squares approach, where

$$
\begin{gathered}
\widehat{\delta}(z)=\left[\left(n h^{q}\right)^{-1} \sum_{j=1}^{n} X_{j} X_{j}^{T} K\left(\frac{z_{j}-z}{h}\right)\right]^{-1}\left\{\left(n h^{q}\right)^{-1} \sum_{j=1}^{n} X_{j} y_{j} K\left(\frac{z_{j}-z}{h}\right)\right\} \\
=\left[D_{n}(z)\right]^{-1} A_{n}(z)
\end{gathered}
$$

and $D_{n}(z)=\left(n h^{q}\right)^{-1} \sum_{j=1}^{n} X_{j} X_{j}^{T} K\left(\frac{z_{j}-z}{h}\right), A_{n}(z)=\left(n h^{q}\right)^{-1} \sum_{j=1}^{n} X_{j} y_{j} K\left(\frac{z_{j}-z}{h}\right), K($. is a kernel function and $h=h_{n}$ is the smoothing parameter for sample size $n$. The intuition behind the above local least-squares estimator is straightforward. Let us assume that $z$ is a scalar and $K($.$) is a uniform kernel. In this case the$ expression for $\widehat{\delta}(z)$ becomes

$$
\widehat{\delta}(z)=\left[\sum_{\left|z_{j}-z\right| \leq h} X_{j} X_{j}^{T}\right]^{-1} \sum_{\left|z_{j}-z\right| \leq h} X_{j} y_{j}
$$

In this case $\widehat{\delta}(z)$ is simply a least squares estimator obtained by regressing $y_{j}$ on $X_{j}$ using the observations of $\left(X_{j}, y_{j}\right)$ that their corresponding $z_{j}$ is close to $z\left(\left|z_{j}-z\right| \leq h\right)$. Since $\delta(z)$ is a smooth function of $z,\left|\delta\left(z_{j}\right)-\delta(z)\right|$ is small when $\left|z_{j}-z\right|$ is small. The condition that $n h^{q}$ is large ensures that we have 
sufficient observations within the interval $\left|z_{j}-z\right| \leq h$ when $\delta\left(z_{j}\right)$ is close to $\delta(z)$. Therefore, under the conditions that $h \rightarrow 0$ and $n h^{q} \rightarrow \infty$, one can show that the local least squares regression of $y_{j}$ on $X_{j}$ provides a consistent estimate of $\delta(z)$. In general it can be shown that

$$
\sqrt{n h^{q}}(\widehat{\delta}(z)-\delta(z)) \rightarrow N(0, \Omega)
$$

where $\Omega$ can be consistently estimated. The estimate of $\Omega$ can be used to con-

struct confidence bands for $\widehat{\delta}(z)$. We use a standard multivariate kernel density estimator with Gaussian kernel and cross validation to choose the bandwidth.

\subsection{Data Sources}

In order to compare the US with European economies concerning their investment in ICT and its effects on productivity and growth, we collected data from the OECD databases covering a wide range of countries over the period 19802004. The countries chosen were based on their availability on ICT data as well as human capital data. The human capital stock data are obtained and updated from Vikram and Dhareshwar (1993). For a full description of their methodology see Vikram, Swanson and Dubey (1995). Their data covers the period 1950 to 1990 and they define human capital stock as total mean years education. We use extrapolation to update the human capital stock up to 2004 . For the update of the data we also take into consideration the human capital stock constructed by Barro and Lee (2001). However, we can not directly use the Barro and Lee data for our analysis since their human capital data are calculated in 5 year intervals. The countries included in this analysis are: Austria, Belgium, Denmark, Finland, France, Germany, Greece, Ireland, Italy, Netherlands, Portugal, Spain, Sweden, UK and USA for comparison purposes. The OECD databases provide data on ICT equipment, Communication equipment, 
Non-ICT equipment, transportation equipment, non residential structures and software in constant and current prices along with GDP and employment data. We use aggregation to obtain ICT investment and the perpetuity method to obtain the capital stocks.

\section{Empirical Findings}

The recent literature examining the effect of human capital on economic growth, see Kalaitzidakis et al (2001) and Mamuneas, Savvides and Stengos (2006), suggests that there exists a nonlinear relationship between human capital and economic growth. In light of the limited country specific evidence regarding the interactions between different types of labor and ICT presented above, we would like to see whether this nonlinear relationship between human capital and growth still persists in the presence of ICT effects. To put it differently, we would like to see whether this nonlinearity was the result of an omitted ICT effect. Based on this literature we include human capital in the nonlinear part of the model with a second smooth coefficient function which includes variables that affect human capital. When estimating the smooth coefficient semiparametric model we obtain estimates of $\theta_{1}($.$) and \theta_{2}($.$) , the output elasticities of$ ICT and human capital respectively. To obtain a graphical analysis for the smooth semiparametric coefficients we need to evaluate the $\theta$ 's at the mean of one of the two variables otherwise we need a three dimension graph. We begin the analysis from the output elasticity of human capital in order to check whether the results obtained here are consistent with the previous literature indicating a nonlinear relationship or whether this nonlinearity was a result of an omitted ICT effect. The output elasticities of human capital are presented in Figure 1. From Figure 1 we can observe that the nonlinear relationship be- 
tween human capital and productivity (and therefore growth) still persists even in the presence of ICT effects. Furthermore, the graph we obtain for the output elasticities of human capital is similar to the one found previously in the literature. The output elasticities of human capital lie in the range between 0.01 to 0.35 , while in Mamuneas, Savvides and Stengos (2006) the range was between 0 and 0.4. Based on the above we can conclude that there does exist a nonlinear relationship between human capital and growth. Moving to the case of ICT capital the smooth coefficient semiparametric model suggests that there also exist a nonlinear relationship between ICT and productivity ${ }^{1}$. Here $\theta_{1}($. is evaluated at the mean of human capital, while in the previous case it was the opposite. The outputs elasticities of ICT capital are presented in Figure 2. Figure 2 indicates that the output elasticities of ICT increase with the level of ICT capital and after a certain threshold they start decreasing for high levels of ICT capital stock. The output elasticities of ICT lie between 0.16 and 0.21. Based on the graph we can see that ICT has a positive but nonlinear effect on productivity, an effects which depends on the level of ICT capital in each country under investigation. To examine the effect per country we have calculated the average output elasticity of ICT per country and the results are presented in Table 1. The results from Table 1 indicate that the average output elasticities of ICT do not vary among countries of the sample used. They range between 0.179 to 0.256 and they appear to be significant. The leading country appears to be the US with the largest elasticity of ICT capital among all the countries of our sample. For comparison purposes we have also constructed a TFP index in which information technology capital contains only IT hardware and software (referred to as ITS). The smooth coefficient semiparametric model

\footnotetext{
${ }^{1}$ This result is consistent with another work on the effect of ICT on productivity using data on US industries, see Ketteni (2006).
} 
used so far is reestimated and the output elasticities of ITS capital are presented in Figure 3. The graphical analysis using only hardware and software as the components of IT capital again indicates a nonlinear relationship between ITS and productivity. The difference between the two Figures is that in the case in which communication equipment are excluded there exists a downward shift of the graph. In this case the output elasticities lie between 0.13 and 0.16 and we obtain less variation across countries ${ }^{2}$. Based on the above analysis we can conclude that the relationship between IT capital and productivity is nonlinear. Additionally, the output elasticities of IT capital indicate that countries benefit when investing in IT. Next, to check if the presence of ICT affects the output elasticities of human capital we plot $\theta_{2}\left(I_{i t}, \bar{H}\right)$. These output elasticities of human capital are presented in Figure 4. Figure 4 shows how the output elasticities change with ICT investment. The graph still suggests a nonlinear relationship. From Figure 4 we observe that in high levels of ICT capital the output elasticities of human capital are higher. They are increasing with the level of ICT capital after a certain threshold. To be able to capture the effect of human capital on the output elasticity of ICT we plot $\theta_{1}\left(\bar{I}, H_{i t}\right)$, that is the output elasticity of ICT evaluated at the mean of ICT capital. The output elasticities estimated are presented in Figure 5. Figure 5 indicates that the nonlinear relationship between ICT and productivity still holds. In low level of human capital we observe that the output elasticities of ICT are decreasing and after a certain threshold (approximately 9 mean years of schooling) we can see an increasing path of the output elasticities of ICT capital. That is in higher levels of human capital stock measured by mean years of schooling we observe higher output elasticities of ICT. This could be due to the fact that in countries

\footnotetext{
${ }^{2}$ The average output elasticities of ITS per country range from 0.118 to 0.176 with the US again having the largest one. The results are available upon request.
} 
with high levels of ICT capital there is a greater need for more educated workers in order to cope with new technologies while this is not the case in countries with low levels of ICT. Based on the analysis conducted we can conclude that both ICT and human capital have a nonlinear relationship with productivity and therefore economic growth. In addition, there exist interactions between the two variables, since in countries with high levels of ICT capital we obtain larger output elasticities of human capital and in countries with more educated workers the output elasticities of ICT capital are higher. We can not say more though on whether ICT causes skill-biased technical change due to the data limitations in distinguishing different types of labor by skill.

\section{Conclusion}

In this paper we compare the productivity performance and the impact of hardware, software and communication equipment on economic growth among the advanced industrialized countries (OECD). We study the influence of ICT on growth by also allowing for the presence of human capital captured by mean years of schooling to interact with ICT and jointly affect economic growth. For the estimation analysis we collected data from the OECD databases covering a wide range of countries over the period 1980-2004. The countries were chosen based on their availability of ICT and human capital data.

There is some evidence that wage differentials observed between high-skilled and low-skilled labor are due to the higher educational attainments of skill labor. Technical change associated with ICT might be skill-biased producing higher wage increases for high-skilled workers relative to low-skilled ones. We use nonparametric techniques to examine the impact of ICT capital to the process of productivity growth by allowing the contribution of various inputs (including 
human capital) as well as that of ICT capital to vary across countries and time. This is accomplished by constructing an index of TFP based on only non-human capital labor and non-ICT capital inputs and by using this index to evaluate the impact of ICT and human capital on TFP growth via semiparametric methods. The smooth coefficient semiparametric model that we use allows us to directly estimate the elasticity of ICT and human capital for each country and time period. In addition we examine the interaction between the human capital and the ICT capital in order to find the interrelationship between the two variables. The recent literature examining the effect of human capital on economic growth suggests that there exists a nonlinear relationship between human capital and growth. Here we investigate whether this nonlinear relationship between human capital and growth still persists in the presence of ICT effects or whether it was a result of an omitted ICT effect. The results from the smooth coefficient semiparametric model for the group of OECD countries in our sample suggest a nonlinear relationship between ICT and productivity along with a nonlinear relationship between human capital stock and productivity, a result consistent with the previous literature. Additionally we find that in high levels of ICT capital the output elasticities of human capital are larger and in high levels of human capital we get higher output elasticities of ICT. In light of the limited country specific evidence regarding the interactions between different types of labor and ICT we leave this for future research. 


\section{References}

[1] Autor, D.H Katz, L.F and A.B Krueger (1997). Computing inequality: Have computers changed the labor market? Cambridge MA, NBER Working Paper, No. 5956.

[2] Barro, R.J and J.W. Lee (2001). International data on educational attainment: Updates and Implications. CID Working Paper, No. 42.

[3] Barua, A. and B. Lee. (1997). The information technology productivity paradox revisited: A theoretical and empirical investigation in the manufacturing sector. The International Journal of Flexible Manufacturing Systems, 9, 145-166.

[4] Basu, S. Fernald, J. G. Oulton, N. and S. Srinivasan (2003). The case of the missing productivity growth: Or does information technology explain why productivity accelerated in the US but not the UK? NBER working paper, No. 10010.

[5] Bermand, E. Bound, J. and Z. Grilicliches (1994).Changes in the demand for skilled labor within US manufacturing: Evidence from the Annual Survey of Manufacturers. The Quarterly Journal of Economics, 109 (2), 367397.

[6] Bermand, E. Bound, J. and S. Machin (1998). Implications of skill-biased technological change : International Evidence. The Quarterly Journal of Economics, 113(4), 1245-1279.

[7] Berndt, E.R and C.J. Morrison. (1995). High-tech capital formation and economic performance in US manufacturing industries. An exploratory analysis. Journal of Econometrics, 65, 9-43. 
[8] Biscourp P. Crepon, B. Heckel, T. and N. Riedinger (2002). How do firms respond to cheaper computers?. Microeconomic evidence for France based on production function approach. January 2002.

[9] Bresnahan, Brynjolfosson, E. and L.M. Hitt. (2002). Information technology, workplace organization and the demand for the skilled labor: Firm level evidence. The Quarterly Journal of Economics, 117 (1).

[10] Chun, H. (2003) Information technology and demand for the educated workers: Disentangling the impacts of adoption versus use. Review of Economic and Statistics, 83 (1), 1-8.

[11] Diewert, W.E. (1976). Exact and superlative index numbers. Journal of Econometrics, 4, 115-146.

[12] Falk, M. and K. Stein (2001). The impact of information technology on high-skilled labor in services. Evidence from firm level data. Mimeo.

[13] Fan, J. (1992). Design-Adaptive nonparametric regression. Journal of the American Statistical Association, 87, 998-1004.

[14] Fan, J. and W. Zhang (1999). Statistical estimation in varying coefficient models. The Annals of Statistics, 27, 1491-1518.

[15] Feldstein, M. (2003). Why is productivity growing faster?. NBER Working Paper, No. 9530.

[16] Gordon, R. J. (2000). Does the 'new economy' measure up to the great inventions of the past. Journal of Economic Perspectives, 14(4), 49-74.

[17] Hoon, Y-S. (2003). Does information technology contributed to economic growth in developing countries? A cross country analysis. Applied Economics Letters, 10 (11), 679-82. 
[18] Jorgenson, D. W. (2001). Information technology and the US economy. American Economic Review, 91(1), 1-32.

[19] Jorgenson, D.W. and K. J. Stiroh. (1999). Information technology and growth. American Economic Review, 89(2), 109-115.

[20] Jorgenson, D.W., K.J. Stiroh and M.S. Ho. (2002). Information technology, education and the sources of economic growth across US industries. April.

[21] Jorgenson, D.W. and K. Motohashi (2005). Information technology and the Japanese economy. NBER Working Paper, No. 11801.

[22] Kalaitzidakis, P., Mamuneas, T., Savvides A. and T. Stengos (2001). Measures of human capital and nonlinearities in economic growth. Journal of Economic Growth, 6, 229-254.

[23] Ketteni. E. (2006). Economic Growth, Productivity and Technological Change. Unpublished Ph.D. thesis, Department of Economics, University of Cyprus.

[24] Kourtellos, A. (2003). Modelling parameter heterogeneity in cross-country regression models. Mimeo, Department of Economics, University of Cyprus.

[25] Li, Q. Huang, C.J. Li, D. and T. Fu. (2001). Semiparametric smooth coefficient models. Journal of Business and Economic Statistics, 20(3), 412-422.

[26] Lucas, R.E. (1967). Adjustment costs and the theory of supply. The Journal of Political Economy, 75(4), 321-334.

[27] Mamuneas, T., Savvides A. and T. Stengos. (2005). Economic development and the return to human capital: A smooth coefficient semiparametric approach. Journal of Applied Econometrics, forthcoming. 
[28] Mankiw, N. Romer, D and D.N. Weil (1992). A contribution to the empirics of economic growth. Quarterly Journal of Economics, 107, 407-37.

[29] Matteucci, N. O’Mahony, M. Robinson, C. and T. Zwick (2005). Productivity, workplace performance and ICT: Industry and firm-level evidence for Europe and the US. Scottish Journal of Political Economy, 52 (3), 359-86.

[30] Morrison, C.J. (1997). Assessing the productivity of information technology equipment in US manufacturing industries. The Review of Economics and Statistics, 79(3), 471-481.

[31] Siegel, D. (1997). The impact of computers on manufacturing productivity growth: A multiple indicators-multiple causes approach. The Review of Economics and Statistics, 79(1), 68-78.

[32] Stiroh, K.J. (1998). Computers, productivity and input substitution. Economic Inquiry, 36(2), 175-191.

[33] Stiroh, K.J. (2002). Information technology and the US productivity revival: What do the industry data say?. American Economic Review, 92(5), 1559-1576.

[34] Vikram, N. and A. Dhareshwar (1993). A new database on physical capital stock: Sources, methodology and results. Rivista de Analisis Economico, 8 (1), 37-59.

[35] Vikram, N. Swanson, E. and A. Dubey (1995). A new database on human capital stock in developing and industrial countries: Sources, methodology and results. Journal of Development Economics, 46, 379-401. 
Table 1: Average Output Elasticities of ICT

\begin{tabular}{lcc}
\hline \hline Country & Output Elasticity & Std. Dev. \\
\hline Austria & 0.193 & 0.017 \\
Belgium & 0.209 & 0.012 \\
Denmark & 0.179 & 0.014 \\
Finland & 0.222 & 0.058 \\
France & 0.228 & 0.046 \\
Germany & 0.208 & 0.009 \\
Greece & 0.241 & 0.064 \\
Ireland & 0.221 & 0.081 \\
Italy & 0.214 & 0.015 \\
Netherlands & 0.206 & 0.011 \\
Portugal & 0.216 & 0.134 \\
Spain & 0.249 & 0.061 \\
Sweden & 0.234 & 0.081 \\
UK & 0.219 & 0.062 \\
USA & 0.256 & 0.075 \\
\hline \hline
\end{tabular}




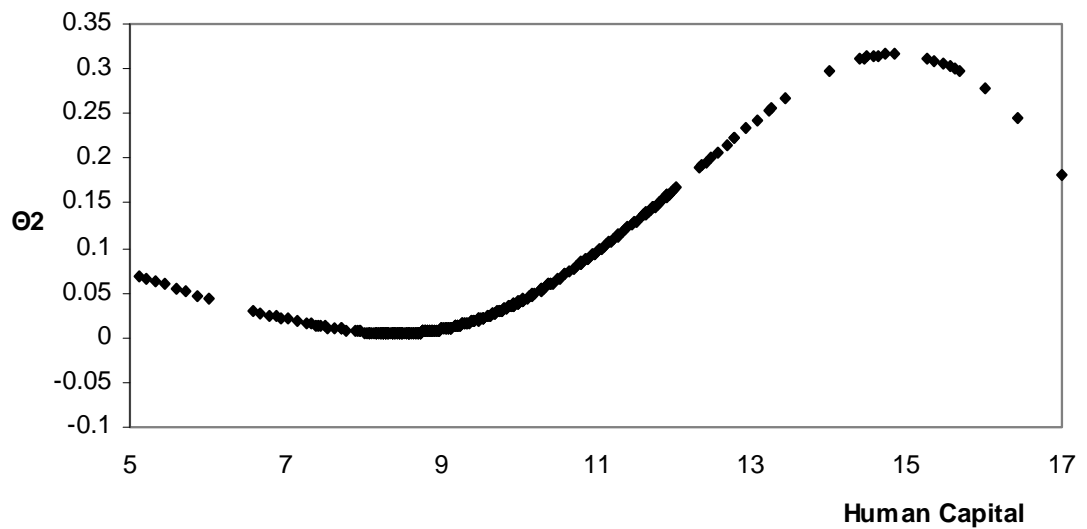

Figure 1: Output elasticities of human capital $\theta_{2}\left(\bar{I}, H_{i t}\right)$

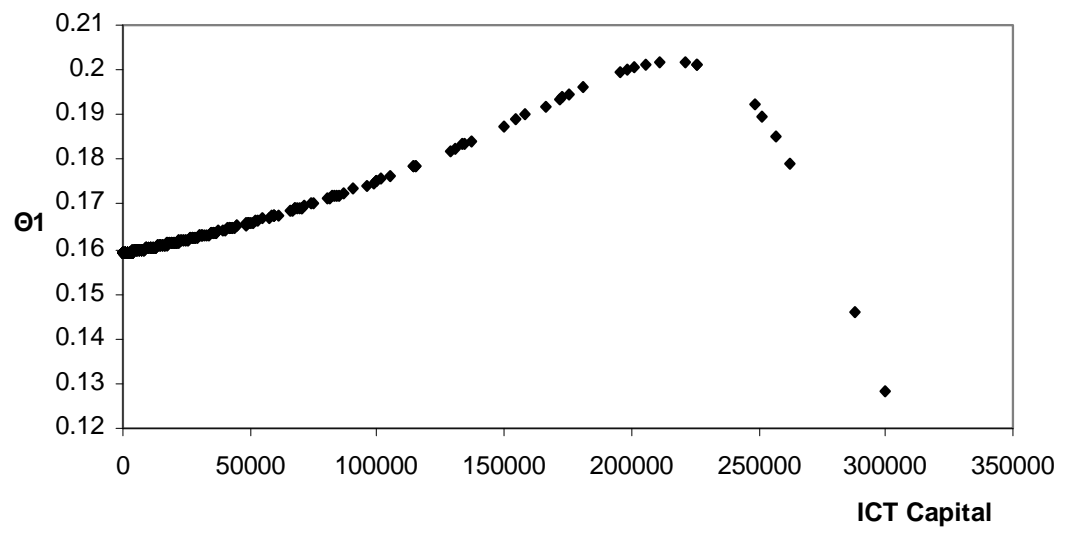

Figure 2: Output elasticities of ICT capital, $\theta_{1}\left(I_{i t}, \bar{H}\right)$ 


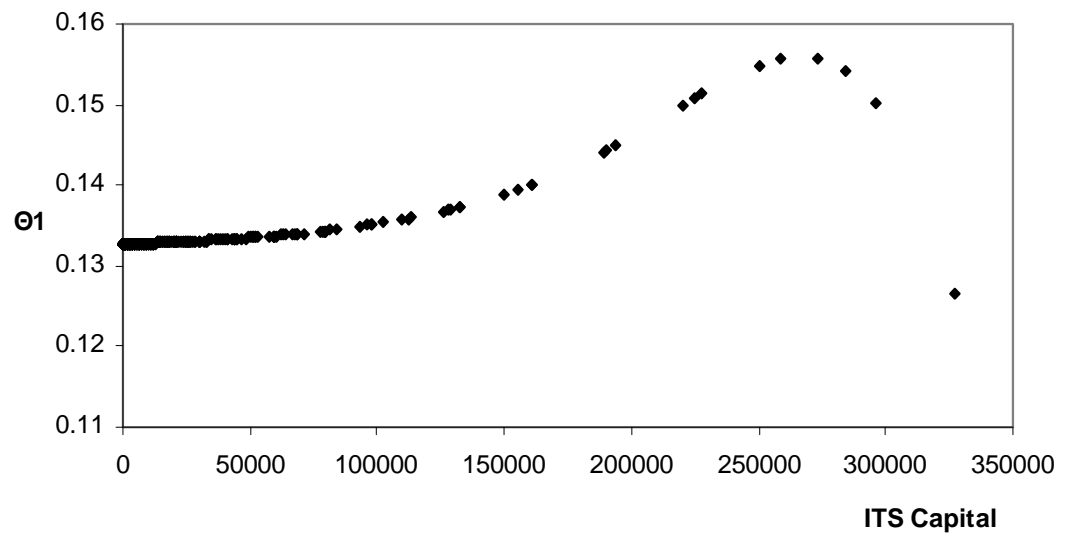

Figure 3: Output elasticities of ITS capital, $\theta_{1}\left(I T S_{i t}, \bar{H}\right)$

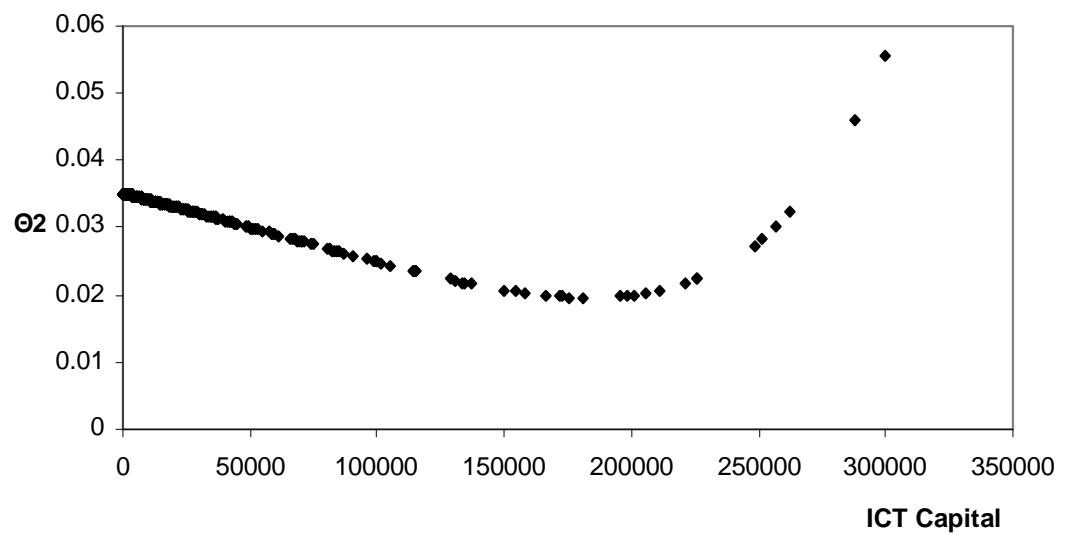

Figure 4: Output elasticities of human capital, $\theta_{2}\left(I_{i t}, \bar{H}\right)$ 


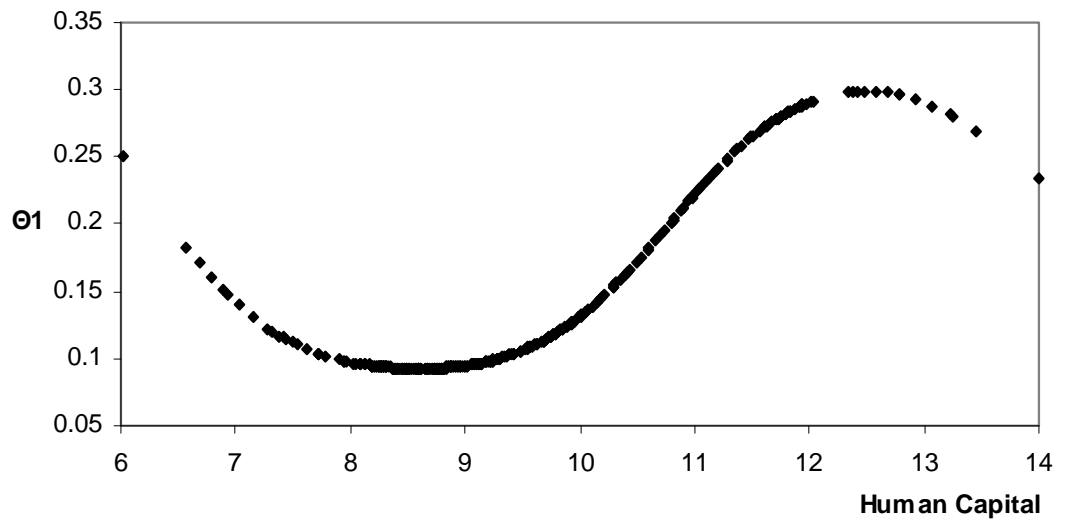

Figure 5: Output elasticities of ICT capital, $\theta_{1}\left(\bar{I}, H_{i t}\right)$ 